\title{
Incidents caused by hemosiderosis in patients with hematologic diseases: results from the Spanish haemovigilance system at national and regional level (Andalusia)
}

Keywords: haemovigilance, CCAA, packed red blood cells, anti neoplastic, SHOT, ferritin levels

\section{Introduction}

The Blood Safety System (Haemovigilance- HV) enables to collect and analyze incidents related to donation, preparation of blood components and transfusion. The purpose is to know the complications and adverse reactions occurred during the transfusion process, to establish effective control measures that can prevent these events. Haemovigilance system should cover the entire transfusion chain. Its objectives are: Understand the side effects: complications and incidents of transfusion, Ensure traceability, Tailor corrective action, Provide early warning system and increase transfusion safety. Among transfusion-related complications, the Hemosiderosis is an incident characterized by a very low level of reporting. We have analyzed Hemosiderosis at national state and inside our CCAA (regions). Post-transfusion hemosiderosis is a frequent complication of hematologic diseases, as well as part of their treatment. It is defined as the accumulation of iron in organs and tissues in patients who are receiving regular transfusions of packed red blood cells. ${ }^{1}$ In patients with anemia and ineffective erythropoiesis, an increase in intestinal iron absorption is produced due to low levels of hepcidin. This iron overload is more serious when these patients require continuous blood transfusions. On the other hand, malignant hematological diseases will require regularly transfusions, either as part of the treatment of the disease itself or as a result of the anemia-inducing effect caused by the anti neoplastic treatment. Iron overload, therefore, will be a common side effect in these patients. It is directly related to the number of transfusions received. A red cell concentrate contains from 200 to $250 \mathrm{mg}$ of iron. After transfusing 10 bags of red blood cells, iron is deposited in tissues, where it can produce toxicity. After 20 packed red blood cells, the risk of developing a secondary hemochromatosis increases. $^{2}$

We intend to investigate the percentage of hemosiderosis reports to the Spanish Haemovigilance system. In the European Union, there are various HV systems, to note French Haemovigilance system: It is governmental, with a complex structure, notification of all adverse effects and mandatory reporting. English Haemovigilance system (SHOT): Financed by scientific societies and professional associations, with simpler structure, notification of serious adverse effects and voluntary reporting. Spanish system (HV): a simpler structure model, with voluntary reporting of adverse events and reactions. Notifications are virtually nonexistent, except in the French system. Although reporting of post-transfusion hemosiderosis is mandatory in the French hemovigilance network since 1994, existing data is limited.
Volume 4 Issue 3 - 2017

\author{
García Ruiz MA, Luque Marta R, Constantin \\ Estefanía M, Chacón Manuel J \\ Hospital Universitario Virgen de las Nieves, Spain
}

Correspondence: García Ruiz María Almudena, Hospital Universitario Virgen de las Nieves, Avda. Fuerzas Armadas NÂ², CP I80 I0, Granada, Spain, Tel +3462285 I331, Email almudena.g.r@gmail.com

Received: March 29, 2017 | Published: April 17, 2017

\section{Patients, materials and methods}

We reviewed the transfusion incidents caused by iron overload which have been reported to the Spanish HV system and the Andalusia HV system, comparing them with the ones notified by our hospital from 2013 to 2016 and their underlying hematologic diseases. ${ }^{3}$

\section{Notifications to the spanish HV system were}

i. 2007:3cases.

ii. $2008: 15$ cases.

iii. 2009:10cases.

iv. 2010:10cases.

v. 2011:16cases.

vi. 2012: 10cases.

vii. 2013: 88 cases.

viii. 2014: 108cases.

ix. 2015: 69cases.

\section{Notifications to the autonomous community of} andalusia were

i. 2007-2012: 0cases.

ii. 2013:71cases.

iii. 2014:90cases.

iv. 2015:Results have not been published yet.

\section{Results}

In 2013, we identified 57cases, 32men and 25women, from 
20 to 87years old, with an average of 56years old, who have been transfused with packed red blood cells. The results vary from $10 \mathrm{CH}$ to $73 \mathrm{CH}$ transfused (average of $25 \mathrm{CH}$ per patient). Post transfusional ferritin levels in all patients were over $1000 \mathrm{ng} / \mathrm{ml}$ with an average of $2869 \mathrm{ng} / \mathrm{ml}$. In 2014 we have notified 76cases to the HV system, from 24 to 83years old, 50men and 26women (average of 56years old). The number of $\mathrm{CH}$ transfused varied from 10 to 130 (average of 31 $\mathrm{CH})$. The number of post-transfusion ferritin ranged between 1,041 and $15,190 \mathrm{ng} / \mathrm{ml}$.

In 2015 , 42cases have been reported: 18 women and $24 \mathrm{men}$, between the ages of 17 and 81 , with an average of 51years old. The number of $\mathrm{CH}$ transfused ranged from 10 to 107 (average of $33.3 \mathrm{CH}$ ). Post-transfusion ferritin ranged between 1.274 and $8.858,4 \mathrm{ng} / \mathrm{ml}$. In 2016, 41 cases have been reported: 30 men and 11 women, between the ages of 6 and 92, with an average of 57years old. The number of $\mathrm{CH}$ transfused ranged from 10 to 71 (average of $36.48 \mathrm{CH}$ ). Posttransfusion ferritin ranged between 1.027, 9 and $35.063,2 \mathrm{ng} / \mathrm{ml}$ (Table 1). Firstly, the largest number of hyperferritinemia cases was found in patients with acute myeloid leukemia. Secondly, in patients with monoclonal gammopathies and thirdly in patients with non-Hodgkin lymphoma. Other diagnoses were myelodysplastic syndrome, chronic lymphocytic leukemia etc (Figure 1).

Table I Post transfusional ferritin levels in all patients

\begin{tabular}{llllll}
\hline Years & Men & Women & Median age & Median CH & Median ferritin \\
\hline 2013 & 32 & 25 & 56 & 25 & $2.869 \mathrm{ng} / \mathrm{ml}$ \\
2014 & 50 & 26 & 56 & 31 & $3.238 \mathrm{ng} / \mathrm{ml}$ \\
2015 & 18 & 24 & 51 & 33 & $3.457 \mathrm{ng} / \mathrm{ml}$ \\
2016 & 30 & 11 & 57 & 36 & $6.961 \mathrm{ng} / \mathrm{ml}$ \\
\hline
\end{tabular}

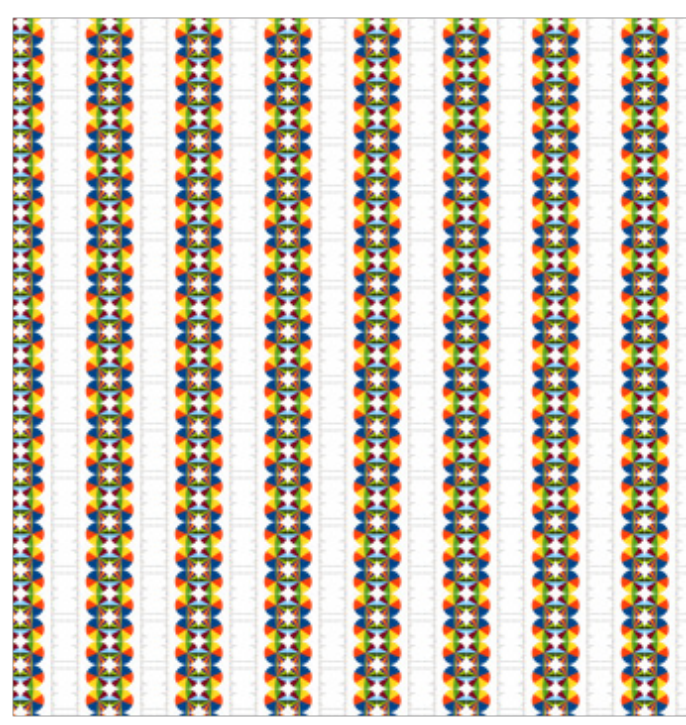

Figure I Other diagnoses were myelodysplastic syndrome, chronic lymphocytic leukemia etc.

\section{Conclusion}

The most frequent cause of hemosiderosis secondary to transfusion in our hospital has been acute leukemia, with a predominance of acute myeloid leukemia over acute lymphoblastic leukemia. It is very important to properly track ferritin levels in patients who are undergoing multiple transfusions, in order to establish chelation therapy when necessary and to prevent the organic damage of secondary hemochromatosis. Looking at the results published by the Andalusian HV system in 2013 and 2014, we can highlight the increase of notifications of post-transfusion hemosiderosis to the hemovigilance system, as well as the increasing number of near-miss reported in 2013. This is valued as an improvement in the notification of such events. Communication of Hemosiderosis cases to the hemovigilance System helps to create protocols for poly transfused patients because of hematologic diseases. Hemovigilance in Spain is, today, a fully integrated tool within the activities carried out by Transfusion Hospital Centers and Services. Among the remaining challenges, we highlight: Getting a more uniform level of notification and moving forward in the optimal use of blood and blood components: safe, effective and efficient.

\section{Acknowledgements}

None.

\section{Conflict of interest}

The author declares no conflict of interest.

\section{References}

1. http://www.msssi.gob.es/profesionales/saludPublica/ medicinaTransfusional/esquemaHemo/hemovigilancia.htm

2. Leo Kodeli S, Renaudier P, Lassale B. Evaluation of transfusion hemochromatosis prevalence, SFVTT-01 study: preliminary results of the SFVTT working group]. Transfus Clin Biol. 2014;21(4-5):182-188.

3. Chaudhary P, Pullarkat V. Deferasirox: appraisal of safety and efficacy in long-term therapy. J Blood Med. 2013;14:101-110. 